\title{
In vitro and in vivo evaluation of enzymatic and antioxidant activity, cytotoxicity and genotoxicity of curcumin-loaded solid dispersions
}

\author{
Igor Silva de Sáa ${ }^{\mathrm{a}}$ Ana Paula Peron ${ }^{\mathrm{b}}$, Fernanda Vitória Leimann ${ }^{\mathrm{a}, \mathrm{c}, \mathrm{d}}$, Getúlio Nicola Bressan ${ }^{\mathrm{e}}$, \\ Bárbara Nunes Krum ${ }^{\mathrm{f}}$, Roselei Fachinetto ${ }^{\mathrm{e}, \mathrm{f}}$, José Pinela ${ }^{\mathrm{c}}$, Ricardo Costa Calhelha ${ }^{\mathrm{c}}$, \\ Maria Filomena Barreiro ${ }^{\mathrm{c}, \mathrm{d}}$, Isabel C.F.R. Ferreira ${ }^{\mathrm{c}, *}$, Odinei Hess Gonçalves ${ }^{\mathrm{a}, \mathrm{c}, \mathrm{d}}$, \\ Rafael Porto Ineu ${ }^{\text {a }}$

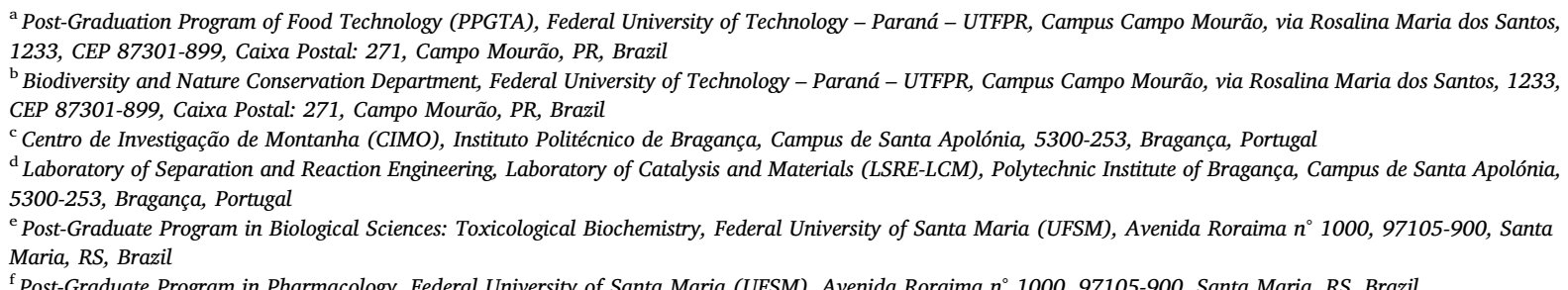

A R T I C L E I N F O

\section{Keywords:}

Bioactivity

Nanoparticles

Solid dispersion

Poloxamer 407

Cholinesterase

Monoamine oxidase

Allium cepa

\begin{abstract}
A B S T R A C T
Curcumin, the main bioactive polyphenolic compound in Curcuma longa L. rhizomes has a wide range of bioactive properties. Curcumin presents low solubility in water and thus limited bioavailability, which decreases its applicability. In this study, cytotoxic effects of curcumin solid dispersions (CurSD) were evaluated against tumor (breast adenocarcinoma and lung, cervical and hepatocellular carcinoma) and non-tumor (PLP2) cells, while cytotoxic and genotoxic effects were evaluated in Allium cepa. The effect of the CurSD on the acetylcholinesterase (AChE), butyrylcholinesterase (BChE), glutathione S-transferase (GST), and monoamine oxidase (MAO A-B) enzymes was determined, as well as its capacity to inhibit the oxidative hemolysis (OxHLIA) and the formation of thiobarbituric acid reactive substances (TBARS). CurSD are constituted by nanoparticles that are readily dispersible in water, and inhibited $24 \%$ and $64 \%$ of the AChE and BChE activity at $100 \mu \mathrm{M}$, respectively. GST activity was inhibited at $30 \mu \mathrm{M}$ while MAO-A and B activity were inhibited at $100 \mu \mathrm{M}$. CurSD showed cytotoxicity against all the tested tumor cell lines without toxic effects for non-tumor cells. No cytotoxic and genotoxic potential was detected with the Allium cepa test. CurSD maintained the characteristics of free curcumin on the in vitro modulation of important enzymes without appreciable toxicity.
\end{abstract}

\section{Introduction}

Turmeric (Curcuma longa L.), with curcumin $\left(\mathrm{C}_{21} \mathrm{H}_{20} \mathrm{O}_{6}\right)$ as its main active compound, is a spice widely used as a coloring and flavoring agent in curry and mustard, being also known as a source of bioactive components (Pandit et al., 2011). It is a yellow-colored nutraceutical polyphenol within the curcuminoid family, which interferes positively with enzyme systems and has antioxidant (Agarwal et al., 2010; Gupta et al., 2010), anti-inflammatory (Chandran and Goel, 2012; Saranya et al., 2018), and anticarcinogenic properties (Prasad et al., 2014), as well as neuroprotective actions (Prasad and Muralidhara, 2014).
Reactive oxygen species (ROS), normally produced in the oxidative metabolism, cause damage to all classes of macromolecules if not neutralized and their excess can lead to oxidative stress (Berg et al., 2014). Among the detoxifying enzymes in organisms are glutathione Stransferases (GSTs), which belong to a multifunctional family of enzymes that catalyze the conjugation of the glutathione molecule with several other molecules (Berg et al., 2014). The evaluation of curcumin on the modulation of GSTs gained increasing importance because in this way it could act in the organism detoxification system. In this context, Monoamine oxidase (MAO; E.C.1.4.3.4) enzyme oxidatively deaminates the monoamines, and the increase in the MAO-B activity was related to

\footnotetext{
* Corresponding author.

E-mail address: iferreira@ipb.pt (I.C.F.R. Ferreira).
} 
neurodegenerative diseases while its inhibition could avoid this process by reducing the oxidative damage. Moreover, the inhibition of MAO-A was associated with an antiapoptotic effect (Ou et al., 2006; Youdim and Bakhle, 2006).

Cholinesterases are enzymes that hydrolyze the neurotransmitter acetylcholine (ACh) in acetate and choline and are found in various parts of the human body being classified in acetylcholinesterase and burthyrylcholinesterase. Therefore, the improvement of the antioxidant status and inhibition of AChE enzyme are suggested as a beneficial tool with therapeutic potential in the prevention of aging and dementia (Araújo et al., 2016). Some flavonoids act by inhibiting AChE activity, increasing the concentration of this cholinergic neurotransmitter (Khan et al., 2018). Like the AChE enzyme, BChE may also be involved in Alzheimer's disease. Studies have been carried out to discover new selective inhibitors of BChE in order to increase the levels of ACh in the cerebral synapses for transmission and cholinergic cognition (Bono et al., 2015; Li et al., 2017; Lockridge, 2015; Pope and Brimijoin, 2018).

The action of curcumin, both on the cholinergic system and on the GSTs, can be efficiently studied using Drosophila melanogaster (DM) tissues, being a reliable model and a powerful genetic tool for the understanding of complex biological problems (Pandey and Nichols, 2011). DM tissues have been used as alternative biological models because they reproduce the signs found in Alzheimer's and Parkinson's diseases or those involving mechanisms of oxidative stress and neurodegeneration (Nass and Przedbordki, 2008). Plant bioassays are also considered satisfactory for monitoring the cytotoxic effects of chemical compounds (Carvalho et al., 2017) and, in particular, meristematic root cells of Allium cepa have been indicated as an efficient test model in the evaluation of cellular toxicity (Campos-Ventura et al., 2016; Moura et al., 2016).

Despite the proven efficacy of curcumin in relation to several biological activities, its low solubility decreases its bioavailability and therapeutic efficacy. However, nanoencapsulation have been used quite successfully to circumvent such low hydro solubility and/or bioavailability of curcumin (de Almeida et al., 2018; Rocha et al., 2014; SilvaBuzanello et al., 2016). Polyoxyethylene-polypropylene block copolymers surfactants (such as Poloxamer 407) are known to enhance dissolution rates and bioavailability of hydrophobic drugs (Vasconcelos et al., 2007). Comparative studies have been carried out demonstrating the improved action of Poloxamers over other encapsulants to obtain stable solid dispersions (Eloy and Marchetti, 2014).

In this study, curcumin was encapsulated by the solid dispersion method and its bioactivity was evaluated regarding enzymatic modulation (acetylcholinesterase- AChE, butyrylcholinesterase - BChE, glutathione S-transferase - GST and monoamine oxidase - MAO A-B), antioxidant activity via antihemolytic and TBARS formation inhibition effects, anti-inflammatory potential through inhibition of NO production and cytotoxicity in tumor and non-tumor cells. Furthermore, genotoxicity and cytotoxicity were also determined in the meristematic Allium cepa in vivo model.

\section{Materials and methods}

\subsection{Materials}

Kolliphor Poloxamer 407 (12,000.00 $\mathrm{g} \mathrm{mol}^{-1}$, Sigma-Aldrich, Brazil), curcumin (Sigma-Aldrich), Tween 80 (Dinâmica) and acetone (Neon) were used to obtain the curcumin solid dispersion. Potassium Bromide (KBr) (Sigma-Aldrich, spectroscopic standard) was used to produce the pellets for Fourier Transform Infrared Spectroscopy. 1Chloro-2,4-dinitrobenzene (CDNB, Sigma-Aldrich), monobasic potassium phosphate (Vetec), anhydrous dibasic potassium phosphate (Neon), reduced glutathione (GSH, Sigma-Aldrich) were used to determine glutathione S-transferase (GST) activity and hydroxymethyl aminomethane buffer (Tris-HCl, Dynamic), 5,5'-dithiobis (2-nitrobenzoic acid) (DTNB, Sigma-Aldrich), acetylthiocholine and butyrylthiocholine iodide were used in the acetylcholinesterase (AChE) and butyrylcholinesterase (BChE) activity assays. Trichloroacetic acid (TCA), 6-hydroxy-2,5,7,8-tetramethylchroman-2-carboxylic acid (trolox) and 2,2'-azobis(2-methylpropionamidine) dihydrochloride (AAPH) (from Sigma-Aldrich) were used in the OxHLIA and TBARS assays. Acetic acid, sulforhodamine B (SRB), ellipticine, dexamethasone, trypan blue, lipopolysaccharide (LPS), tris-(hydroxymethyl)aminomethane (TRIS) (from Sigma-Aldrich), dimethyl sulfoxide (DMSO) (from Fisher Scientific), Dulbecco's Modified Eagle's Medium (DMEM) and RPMI-1640 medium, fetal bovine serum (FBS), Hank's balanced salt solution (HBSS), L-glutamine, nonessential amino acid solution $(2 \mathrm{mM})$, penicillin/streptomycin solution $\left(100 \mathrm{U} \cdot \mathrm{mL}^{-1}\right.$ and $100 \mathrm{mg} \mathrm{mL}^{-1}$, respectively), trypsin and EDTA (from Hyclone) were used in the cytotoxic and anti-inflammatory activity assays. All other chemicals were of analytical grade and purchased from common sources. Water was treated in a Milli-Q water purification system (TGI Pure Water Systems) before use.

\subsection{Preparation of curcumin solid dispersions and physicochemical characterization}

Curcumin solid dispersion was obtained using the methodology described by Almeida et al. (de Almeida et al., 2018) with minor modifications. Poloxamer 407 (3.600 g) and Tween $80(0.360 \mathrm{~g})$ were solubilized in acetone $(36 \mathrm{~mL})$ under gentle stirring at $25^{\circ} \mathrm{C}$ for $5 \mathrm{~min}$. Curcumin $(0.360 \mathrm{~g})$ was added to the solution, stirred for $1 \mathrm{~min}$ and then sonicated (Fisher-Scientific, Ultrasonic Dismembrator 120 W, 1/8" tip) for $180 \mathrm{~s}$ under a pulse regime ( $30 \mathrm{~s}$ on, $10 \mathrm{~s}$ off). Solvent was evaporated for $18 \mathrm{~h}$ at $50^{\circ} \mathrm{C}$ and the obtained solid dispersion stored at $10^{\circ} \mathrm{C}$ protected from light.

Solid dispersion (10 mg) or curcumin (1 mg) were dispersed in water $(10 \mathrm{~mL})$ to qualitatively evaluate the dispersibility. Differential Scanning Calorimetry (DSC, Perkin Elmer 4000) was used to evaluate both the physical state of curcumin and solid dispersions. For that, approximately $10 \mathrm{mg}$ of the samples were placed in closed aluminum pans and heated from 0 to $300^{\circ} \mathrm{C}$ at $20^{\circ} \mathrm{C} \cdot \mathrm{min}^{-1}$ and nitrogen at $50 \mathrm{~mL} \mathrm{~min}^{-1}$. Infrared spectra (Shimadzu - IR Affinity-1) were acquired using $\mathrm{KBr}$ pellets containing approximately $1 \%$ of each sample at $2 \mathrm{~cm}^{-1}$ in the spectral range of $400-4000 \mathrm{~cm}^{-1}$. Peaks were normalized to allow comparison between spectra. Particle's morphology was accessed by Transmission Electron Microscopy (TEM, Jeol JEM 2100, $200 \mathrm{kV}$ ) by carefully placing the samples on 300 mesh parlodiumcoated cooper grids. Laser Diffraction (Malvern Mastersizer 3000) was used to determine particle's size distribution using water as the dispersant medium. X-ray diffraction patterns were acquired using a Bruker equipment at $1.1 \mathrm{kVA}$ and $5.9^{\circ} \cdot \mathrm{min}^{-1}$ from 2 to $60^{\circ}$. For comparison purposes, a physical mixture of curcumin and Poloxamer 407 was obtained by manually mix both components at the same concentration used for solid dispersions.

\subsection{Antioxidant and enzymatic activity}

\subsubsection{Enzymatic assays}

Biological samples preparation. Drosophila melanogaster wild-type (Harwich strain) was obtained from the National species Stock Center (Bowling Green, OH, USA). Flies were maintained and reared on cornflower medium ( $2 \% \mathrm{w} / \mathrm{v}$ sucrose, $1.6 \% \mathrm{w} / \mathrm{v}$ powdered milk, $0.2 \%$ salt and $0.05 \% \mathrm{w} / \mathrm{v}$ methylparaben) at constant temperature $\left(24^{\circ} \mathrm{C}\right)$ and relative humidity (60\%) under $12 \mathrm{~h}$ dark/light cycle conditions until treatment. 100 flies were anaesthetized in ice and homogenized in $0.05 \mathrm{M}$ Tris-HCl buffer, $\mathrm{pH}$ 7.4, 1:10 [flies/volume $(\mu \mathrm{L})$ ]. The homogenate was centrifuged at $12,000 \mathrm{rpm}$ for $10 \mathrm{~min}$, and the supernatant (S1) used for the biochemical assays. Protein content was determined as described by (Bradford, 1976), using bovine serum albumin (BSA) as the standard.

Acetylcholinesterase (AChE) and butyryl cholinesterase (BChE) 
activities. AChE (E.C.3.1.1.7) and BChE (E.C.3.1.1.8) activities were determined using the method proposed by Ellman (1959) with minor modifications. The reaction medium contained $100 \mu \mathrm{L}$ of $0.50 \mathrm{M}$ Tris$\mathrm{HCl}$ (pH 7.4), $100 \mu \mathrm{L}$ of $10 \mathrm{mM}$ DTNB, $75 \mu \mathrm{L}$ of S1 and $25 \mu \mathrm{L}$ of curcumin solid dispersion (at the final concentrations of $0-100 \mu \mathrm{M}$ or until significant inhibition). Samples were incubated for $2 \mathrm{~min}$ and $100 \mu \mathrm{L}$ of the $8 \mathrm{mM}$ acetylthiocholine (for AChE activity) or butyrylthiocholine (for BChE activity) was added at the end and completed with distilled water $(1000 \mu \mathrm{L})$. The reading was monitored at a wavelength of $412 \mathrm{~nm}$ for 3 minat intervals of $30 \mathrm{~s}$ using a UV-Vis spectrophotometer (OceanOptics model USB650). Enzymatic activity was expressed in percentage (\%) relative to the respective control (set as 100\% activity for water or DMSO depending on the group).

Glutathione S-transferase (GST) activity. GST (E.C. 2.5.1.18) activity was determined based on the procedure of Habig et al. (1974). The reaction mixture contained $400 \mu \mathrm{L}$ of $40 \mathrm{mM}$ TFK buffer ( $\mathrm{pH} 7.5$ ), $520 \mu \mathrm{L}$ of distilled water, $10 \mu \mathrm{L}$ of the solid dispersion (at final concentrations of $0-100 \mu \mathrm{M}$ or until significant inhibition) and $50 \mu \mathrm{L} \mathrm{S1}$ were incubated for $2 \mathrm{~min}$. After incubation, $10 \mu \mathrm{L}$ of $100 \mathrm{mM}$ reduced glutathione and $10 \mu \mathrm{L}$ of $100 \mathrm{mM}$ CDNB (1-chloro-2,4-dinitrobenzene) were added. Then, reading was performed at $340 \mathrm{~nm}$ for $2 \mathrm{~min}$ every $30 \mathrm{~s}$ on the aforementioned UV-Vis spectrophotometer. Enzymatic activity was expressed in percentage (\%) relative to the respective control (set as $100 \%$ activity for water or DMSO depending on the group).

MAO activity. For the in vitro MAO (E.C. 1.4.3.4) activity analyzes, rats brain samples were used under the project approved by the Ethics Commission on Animal Use of the Federal University of Santa Maria under process number $091 / 2013$. Samples have been stored at $-80^{\circ} \mathrm{C}$ until use and half of each brain (containing cortical and subcortical regions) was homogenized in assay buffer $\left(16.8 \mathrm{mM} \mathrm{Na} \mathrm{Na}_{2} \mathrm{HPO}_{4}\right.$, $10.6 \mathrm{mM} \mathrm{KH}_{2} \mathrm{PO}_{4}$, and $3.6 \mathrm{mM} \mathrm{KCl}, \mathrm{pH}$ 7.4). MAO-A and MAO-B activities were determined in rat brain preparations by using kynuramine as a substrate, as previously described (de Oliveira et al., 2015; SotoOtero et al., 2001; Villarinho et al., 2012). Activity of A and B isoforms were pharmacologically isolated by incorporating $250 \mathrm{nM}$ pargyline (selective MAO-B inhibitor) or $250 \mathrm{nM}$ clorgyline (selective MAO-A inhibitor) into the reaction mixture. The reaction mixture (containing curcumin, Poloxamer or the solid dispersion and brain homogenates and inhibitors) was pre-incubated at $37^{\circ} \mathrm{C}$ for $10 \mathrm{~min}$, and the reaction started upon addition of $50 \mu \mathrm{L}$ of kynuramine $(60 \mu \mathrm{M})$. Curcumin was tested at $100 \mu \mathrm{g} \mathrm{mL}^{-1}$, solid dispersion at $10-100 \mu \mathrm{g} \mathrm{m}^{-1}$ and Poloxamer at $100 \mu \mathrm{gL}^{-1}$ (to verify any per se effect on MAO activity). Assays were performed in duplicate in a final volume of $500 \mu \mathrm{L}$ containing $0.25 \mathrm{mg}$ of protein and incubated at $37^{\circ} \mathrm{C}$ for $30 \mathrm{~min}$. Fluorescence was determined at $315 \mathrm{~nm}$ for excitation and $380 \mathrm{~nm}$ for emission (Morinan and Garratt, 1985).

In all performed enzymatic tests it was evaluated if Poloxamer showed per se effect in the lower solid dispersion concentration in which any modulation was detected.

\subsubsection{Oxidative hemolysis inhibition assay (OxHLIA)}

The antihemolytic activity was assessed using the method described by Takebayashi et al. (2012) with some modifications. Sheep blood samples were collected from healthy animals and centrifuged at $1000 \mathrm{~g}$ for $5 \mathrm{~min}$ at $10^{\circ} \mathrm{C}$. Plasma and buffy coats were discarded and erythrocytes were firstly washed once with $\mathrm{NaCl}(150 \mathrm{mM})$ and three times with phosphate-buffered saline (PBS, pH 7.4) (Evans et al., 2013). The erythrocyte pellet was then resuspended in PBS at $2.8 \%(\mathrm{v} / \mathrm{v})$. Using a flat bottom 48 -well microplate, $200 \mu \mathrm{L}$ of erythrocyte solution was mixed with $400 \mu \mathrm{L}$ of either PBS solution (control), sample dispersed in $\mathrm{PBS}$, or water (for complete hemolysis). Trolox was used as a positive control. After pre-incubation at $37^{\circ} \mathrm{C}$ for $10 \mathrm{~min}$ with shaking, AAPH ( $200 \mu \mathrm{L}, 160 \mathrm{mM}$ in PBS) was added and the optical density measured in a microplate reader (Bio-Tek Instruments, ELX800) at $690 \mathrm{~nm}$. After that, the microplate was incubated under the same conditions and the optical density was measured every $10 \mathrm{~min}$ at the same wavelength for approximately $300 \mathrm{~min}$. The percentage of the erythrocyte population that remained intact $(P)$ was calculated by Equation (1), where $S_{t}$ and $S_{0}$ correspond to the optical density of the sample at $t$ and $0 \mathrm{~min}$, respectively, and $\mathrm{CH}_{0}$ is the optical density of the complete hemolysis at 0 min.

$P \%=100\left(\frac{S_{t}-C_{0}}{S_{0}-C H_{0}}\right)$

Results were expressed as delayed time of hemolysis $(\Delta t)$, calculated by Equation (2), where $\mathrm{Ht}_{50}$ is the $50 \%$ hemolytic time (min) graphically obtained from the hemolysis curve of each sample concentration.

$\Delta \mathrm{t}(\min )=\mathrm{Ht}_{50}$ (sample) $-\mathrm{Ht}_{50}$ (control)

The $\Delta \mathrm{t}$ values were then correlated to the different sample concentrations (Takebayashi et al., 2012) and, from the obtained correlation, the concentration able to promote a $\Delta$ t haemolysis delay was calculated. The results were expressed as $\mathrm{IC}_{50}$ values $\left(\mu \mathrm{g} \cdot \mathrm{mL}^{-1}\right)$ at $\Delta \mathrm{t} 60$ and $120 \mathrm{~min}$, i.e. the sample concentration required to keep $50 \%$ of the erythrocyte population intact for 60 and $120 \mathrm{~min}$.

\subsubsection{Thiobarbituric acid reactive substances (TBARS) formation inhibition assay}

The capacity of the sample to inhibit the formation of thiobarbituric acid reactive substances (TBARS), such as malondialdehyde generated from the ex vivo decomposition of lipid peroxidation products, was evaluated using porcine brain cell homogenates, following the method described previously by Pinela et al. (2012). Trolox was used as positive control. The results were expressed as $\mathrm{IC}_{50}$ values $\left(\mu \mathrm{g} \cdot \mathrm{mL}^{-1}\right)$, i.e. the sample concentration providing $50 \%$ of antioxidant activity.

\subsection{Cytotoxic assays in cell lines and anti-inflammatory activity assay}

To assess the cytotoxicity of the sample, the sulforhodamine (SRB) assay was performed according to a procedure previously established by Abreu et al. (2011). Curcumin solid dispersion was dispersed in water at $8 \mathrm{mg} \mathrm{mL}^{-1}$ and this stock solution used to prepare successive dilutions. MCF-7 (breast adenocarcinoma), NCIH460 (non-small cell lung carcinoma), HeLa (cervical carcinoma) and HepG2 (hepatocellular carcinoma) from DSMZ (Leibniz-Institute DSMZ - German Collection of Microorganisms and Cell Cultures) were selected as human tumor cell lines. Porcine liver cells (PLP2), a primary cell culture, were prepared according to the procedure described by Abreu et al. (2011). These cells were treated for $48 \mathrm{~h}$ with the different sample solutions and the SRB assay was followed (Souza et al., 2015). Ellipticine was used as a positive control. The results were expressed as $\mathrm{GI}_{50}$ values (concentration that inhibited $50 \%$ of the net cell growth).

For the anti-inflammatory activity determination, the lipopolysaccharide (LPS)-induced nitric oxide (NO) production by a murine macrophage (RAW 264.7) cell line was quantified as nitrite concentration in the culture medium (Sobral et al., 2016). The effect of the tested compounds in the absence of LPS was also evaluated, in order to observe if they induced changes in NO basal levels. In negative controls, no LPS was added. For the NO determination, a Griess Reagent System kit containing sulfanilamide, N-1-naphthylethylenediamine dihydrochloride (NED) and nitrite solutions was used. Dexamethasone was used as a positive control. The results were expressed as IC $_{50}$ values $\left(\mu \mathrm{g} . \mathrm{mL}^{-1}\right.$ ), i.e. compound concentration providing $50 \%$ of NO production inhibition.

\subsection{Cytotoxicity and genotoxicity test in root meristem cells of Allium cepa}

Cytotoxicity and genotoxicity were evaluated following the methodology described by Fiskesjö (1993). Initially, onion bulbs were placed in aerated flasks with distilled water at room temperature (approximately $27^{\circ} \mathrm{C}$ ) to obtain $2.0 \mathrm{~cm}$ long roots. Experiments were carried out 
in triplicate. Before placing the roots in contact with their respective samples, roots were collected and fixed to serve as control of the bulb itself. Then, the remaining roots were placed in their respective treatments for $24 \mathrm{~h}$. After $24 \mathrm{~h}$, roots were taken and fixed and the remaining roots of each bulb were returned to their respective treatments where they remained for another $24 \mathrm{~h}$ and roots were again collected and fixed. The exposure times 24 and $48 \mathrm{~h}$ were chosen with the purpose of evaluating the effect of treatment groups on more than one cell cycle. A negative control with distilled water and a positive control with pure paracetamol $\left(800 \mathrm{mg} . \mathrm{L}^{-1}\right)$ in distilled water were prepared. In this concentration, paracetamol is known to be cytotoxic, genotoxic and clastogenic the meristematic cells of roots of $A$. cepa. In the same way, for the two controls, roots were collected at 0,24 and $48 \mathrm{~h}$. Roots were fixed in Carnoy 3:1 (ethanol: acetic acid) for $24 \mathrm{~h}$ (three roots per bulb were taken). On average, 03 slides per onion bulb were mounted (Paula and Pinto-Maglio, 2015) and analyzed under an optical microscope at 400x magnification. For each onion bulb 1000 cells were analyzed at a given exposure time. Cells were observed in interphase, prophase, metaphase, anaphase and telophase. From this analysis, mitotic index (MI) were determined by Equation (3), where $n_{\text {mitosis }}$ is total number of cells in mitosis and $n_{\text {total }}$ is total number of cells analyzed.

$M I=100 \frac{n_{\text {mitosis }}}{n_{\text {total }}}$

The genotoxic potential of each treatment was evaluated by the frequency of micronucleated cells, C-metaphase, anaphase and telophase bridges, cells with adhesions, nuclear buds and multipolar anaphases.

\subsection{Statistical analysis}

Statistical analysis for the enzymatic tests was performed using the software GraphPad Prism version 6.0 (Graph Pad, USA) using one-way ANOVA followed by Tukey's post hoc test at a significance level of 0.05 . Data obtained in the enzymatic assays were expressed as mean \pm SEM (Standard Error of the Mean). The SPSS Statistics software (IBM SPSS Statistics for Windows, Version 22.0. Armonk, NY: IBM Corp.) was used to analyse differences among the two samples in the OxHLIA and TBARS assays by applying a two-tailed paired Student's t-test at a $5 \%$ significance level. Significant differences were considered when the $p$ value was lower than 0.05 . The statistical analysis of cytotoxicity and genotoxicity in A. cepa was performed on the statistical platform $\mathrm{R}(\mathrm{R}$ Core Team, 2015) by the tests of normality of Shapiro-Wilk and homogeneity of Hartley to verify the heterogeneity of the variances of the treatments. In order to detect statistical differences between the exposure times, Kruskal-Wallis non-parametric test was used, with Dunn's post test, considering a significant $p<0.05$.

\section{Results and discussion}

\subsection{Characterization of the curcumin solid dispersions}

Fig. 1 (a) shows a Transmission Electron Microscopy image of the solid dispersion. Curcumin and the solid dispersion were dispersed in water as one may see in Fig. 1 (b). Particles size distribution of the solid dispersion are presented in Fig. 1 (c). Fig. 2 shows the results of (a) Differential Scanning Calorimetry (DSC), (b) Infrared Spectroscopy (FTIR) and the (c) X-ray Diffraction patterns of curcumin, the solid dispersion, physical mixture (in the same mass proportion of Poloxamer 407:curcumin found in the solid dispersion), and Poloxamer 407. DSC and FTIR of physical mixtures with different Poloxamer:curcumin ratios are presented in Figs. S1 and S2 (Supplementary Material).

Curcumin solid dispersion was readily dispersible in water demonstrating an increased water affinity when compared to the highly hydrophobic curcumin as demonstrated by Kaminaga et al. (2003). Light Scattering analysis showed that $50 \%$ of the particles was smaller than

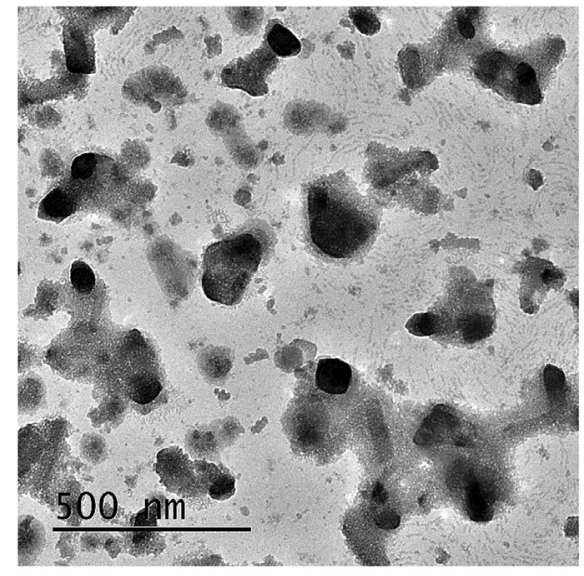

(a) Transmission Electron Microscopy image of the curcumin solid dispersion.

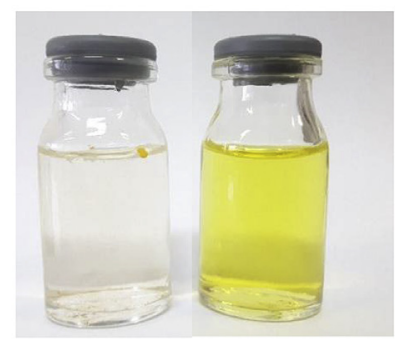

(b) Image of the aqueous dispersions containing curcumin (right) and the curcumin solid dispersion (left).

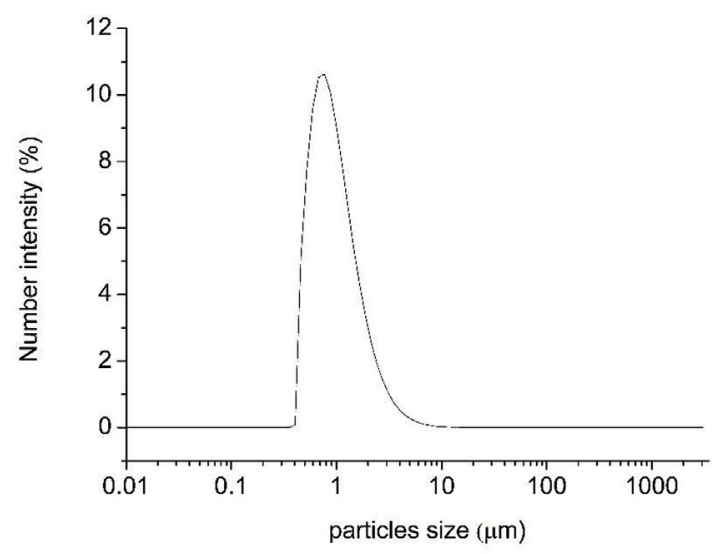

(c) Particles size distribution of the solid dispersion nanoparticles.

Fig. 1. Results of the nanoparticles characterization: (a) Transmission Electron Microscopy images; (b) images of the aqueous dispersions containing curcumin and the solid dispersion and (c) particles size distribution of the solid dispersion.

$0.937 \pm 0.010 \mu \mathrm{m}$ and TEM images showed irregular shaped particles. The difference between the sizes found by Light Scattering and TEM suggest that some agglomeration occurred during size measuring.

Poloxamer 407 and curcumin melted at $56.8^{\circ} \mathrm{C}$ and $179.0^{\circ} \mathrm{C}$, respectively, which is in agreement with the literature. Curcumin melting peak was also found in the physical mixture, nevertheless attenuated, probably due to the low curcumin concentration in the sample (this can also be seen in the physical mixtures with high curcumin concentration compiled in the Supplementary Material). Melting peak was not detected in the solid dispersion suggesting that curcumin is forming an 


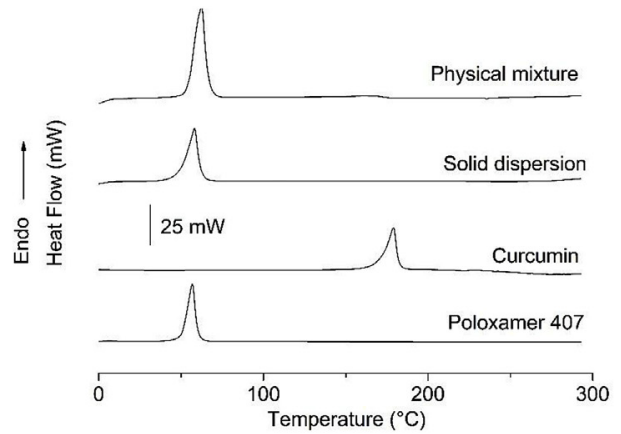

(a) DSC thermograms of curcumin, solid dispersion, Poloxamer 407 and physical

mixture (Poloxamer and curcumin mixed in the same proportion found in the solid dispersion).

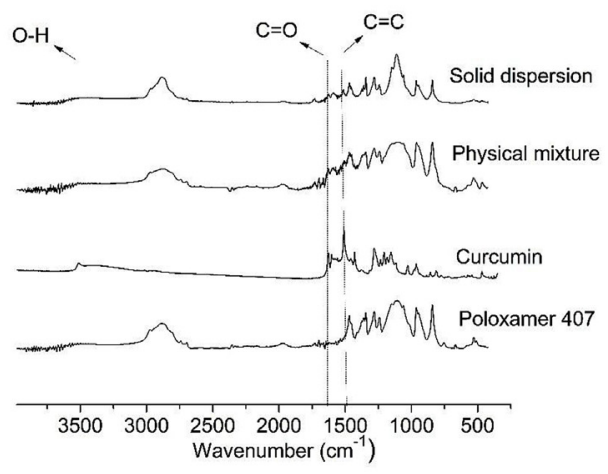

(b) FTIR spectra of curcumin, solid dispersion, Poloxamer 407 and physical mixture (Poloxamer and curcumin mixed in the same proportion found in the solid dispersion).

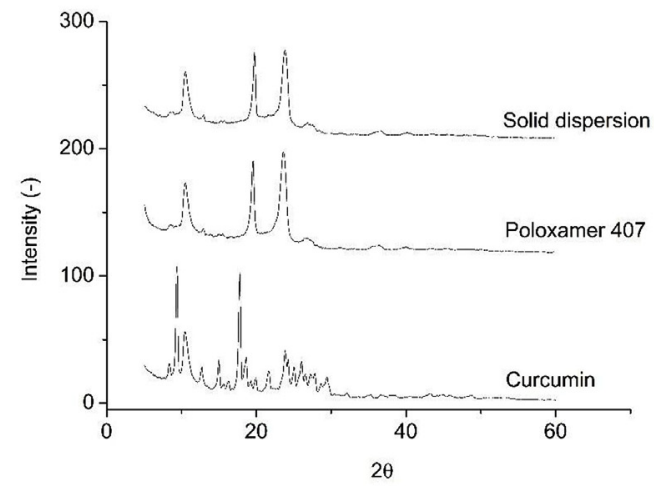

(c) X-ray diffraction patterns of curcumin, solid dispersion and Poloxamer 407.

Fig. 2. Results of the nanoparticles characterization: (a) DSC; (b) FTIR; and (c) $\mathrm{X}$-Ray diffraction.

amorphous phase in the polymeric matrix. In the FTIR spectra of curcumin it is possible to identify the characteristic bands of this compound at $3510 \mathrm{~cm}^{-1}$ (attributed to the $\mathrm{O}-\mathrm{H}$ groups), $1630 \mathrm{~cm}^{-1}(\mathrm{C}=\mathrm{O}$ groups) and $1500 \mathrm{~cm}^{-1}(\mathrm{C}=\mathrm{C}$ bonds). Poloxamer 407 exhibited characteristic absorption bands at approximately $2900 \mathrm{~cm}^{-1}(\mathrm{C}-\mathrm{H})$ and $1110 \mathrm{~cm}^{-1}(\mathrm{C}-\mathrm{O})$. Hydroxyl absorption band is relatively intense in the curcumin spectrum and was attenuated in the physical mixture (again this effect can be seen in the physical mixtures with high curcumin concentration - Supplementary Material). This band was absent in the FTIR spectrum of the solid dispersion, corroborating DSC results and also suggesting that curcumin is entrapped inside the poloxamer matrix. The crystalline nature of poloxamer and curcumin is demonstrated by the X-Ray diffraction patterns (Fig. 2c). Again, curcumin diffraction peaks were not detected in the solid dispersion sample in agreement with DSC and FTIR results.

\subsection{Antioxidant and enzymatic activity}

\subsubsection{Acetylcholinesterase (AChE) and butyrylcholinesterase (BChE)} activity

Figs. 3 and 4 show the results of AChE and BChE activity, respectively, in Drosophila melanogaster tissue in the presence of curcumin and curcumin solid dispersion.

It is worth noting that in the case of the solid dispersions, acetylcholinesterase (AChE) and butyrylcholinesterase (BChE) enzimatic activity were determined without previous dissolution in any organic solvent, meaning that, in these cases, the nanoparticles were dispersed in water. Activity in the presence of pure curcumin was determined in water and also in DMSO. When dispersed only in water, curcumin did not influence AChE activity at $50 \mu \mathrm{M}$, if compared to the control group. Poloxamer 407 did not presented influence per se on the enzyme activity. Curcumin solid dispersion $(25$ and $50 \mu \mathrm{M})$ decreased the AChE activity ( $<<0.05$ and $\mathrm{p}<0.0001$, respectively) and curcumin solubilized in DMSO $4 \%$ also inhibited the enzyme activity at $25 \mu \mathrm{M}$. In the case of BChE, activity was influenced by curcumin in DMSO at $30 \mu \mathrm{M}$ but no inhibition was detected when curcumin was dispersed in water at $100 \mu \mathrm{M}$. Curcumin solid dispersion was able to inhibit BChE activity at $100 \mu \mathrm{M}$.

The influence of pure curcumin on AChE and BChE was demonstrated by Abbasi et al. (2012), but the activity of curcumin in the form of solid dispersion, in aqueous medium, was never investigated. To be able to inhibit the enzymes when in water is an important achievement since it demonstrates that the hydrophobic behavior of curcumin was overcome by its transformation into an amorphous solid dispersion.

\subsubsection{Glutathione S-transferase (GST) activity}

Fig. 5 shows the GST activity in the presence of curcumin and curcumin solid dispersion.

Curcumin solid dispersion in water caused a significant decrease in the glutathione S-transferase activity $(\mathrm{p}<0.01$ and $\mathrm{p}<0.0001)$ at $3 \mu \mathrm{M}$ and $10 \mu \mathrm{M}$, respectively. Curcumin inhibited $(\mathrm{p}<0.0001)$ the activity at 10 and $30 \mu \mathrm{M}$ when previously dissolved in DMSO. No influence on GST was detected for Poloxamer 407 alone and also for curcumin in water, demonstrating the improved hydrophilicity of the solid dispersion. It was demonstrated that curcumin was showed to influence the antioxidant capacity of some enzymes in the body (Agarwal et al., 2010). In addition, phenolic compounds interact with GST modulating its action (Hayeshi et al., 2007).

\subsubsection{MAO activity}

Activity of MAO-A and MAO-B isoforms is presented in Figs. 6 and 7, respectively.

P407-curcumin inhibited both isoforms of MAO at concentration of $100 \mu \mathrm{M}(\mathrm{p}<0.0001)$ while no effect was detected for free curcumin on MAO activity at same concentration suggesting that the incorporation of curcumin into P407 facilitates its interaction with MAO inhibiting this enzyme. MAO catalyzes the oxidative deamination of biogenic amines playing an important role in some neurological conditions (Youdim and Bakhle, 2006). The reaction catalyzed by MAO produces hydrogen peroxide, a source of hydroxyl radicals, and MAO inhibitors might, therefore, be useful in managing pathologies which are associated with oxidative stress (Bianchi et al., 2005; Youdim and Bakhle, 2006).

\subsubsection{Antihemolytic and TBARS formation inhibition activities}

The results of the OxHLIA and TBARS assays, given as sample 

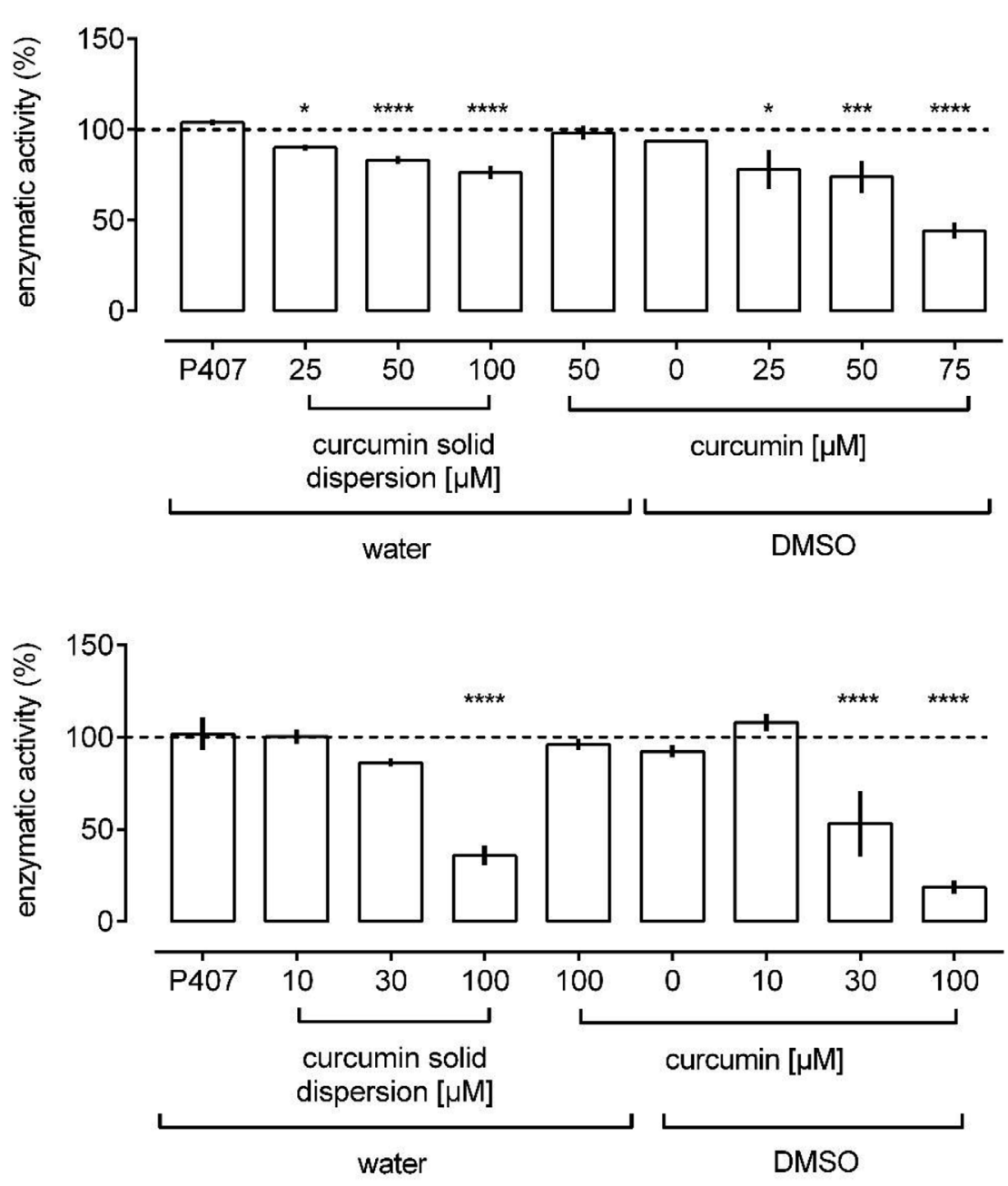

Fig. 3. Effect of curcumin solid dispersion (concentration of $25-100 \mu \mathrm{M})$ and curcumin $(25-75 \mu \mathrm{M})$ on acetylcholinesterase (AChE) activity in Drosophila melanogaster tissue in vitro. Values are mean $\pm \operatorname{SEM}(\mathrm{n}=4$ per group). Significance determined by one-way analyses of variance (ANOVA) followed by Tukey test. *p $<0.05$; $* * * \mathrm{p}<0.001 ; * * * * \mathrm{p}<0.0001$ in comparison to control (P407 = Poloxamer; DMSO $=$ dimethyl sulfoxide).
Fig. 4. Effect of curcumin solid dispersion (concentration of $10-100 \mu \mathrm{M})$ and curcumin $(10-100 \mu \mathrm{M})$ on butyrylcholinesterase (BChE) activity in Drosophila melanogaster tissue in vitro. Values are mean $\pm \operatorname{SEM}(n=4$ per group). Significance determined by one-way analyses of variance (ANOVA) followed by Tukey test. ${ }^{* * *} \mathrm{p}<0.0001$ in comparison to control in comparison to control (P407 = Poloxamer 407; DMSO = dimethyl sulfoxide). concentration needed to protect $50 \%$ of the erythrocyte population from the hemolytic action caused by the oxidizing agent for 60 and $120 \mathrm{~min}$, or to provide $50 \%$ of antioxidant activity, respectively, are presented in Table 1 . The lower $\mathrm{IC}_{50}$ values correspond to a higher antioxidant capacity.

The OxHLIA assay is a suitable model to study free radical-induced oxidative damage of biological membranes and the antioxidant effects of curcumin solid dispersion. Sheep erythrocytes were subjected to the oxidizing action of the hydrophilic free radical initiator AAPH. In a first instance, the (peroxyl) radicals formed from the thermal decomposition of this oxidizing agent attack the erythrocytes membrane, eventually causing its lysis. As a consequence, lipophilic (alkyl) radicals are generated through a lipid peroxidation phenomenon, which also attack the membranes (Prieto and Vázquez, 2014). In fact, the erythrocytes membrane is rich in polyunsaturated fatty acids and thus very susceptible to free radical-mediated peroxidation (Deng et al., 2006). Table 1 shows that $165 \pm 5 \mu \mathrm{g} \mathrm{mL}^{-1}$ and $297 \pm 9 \mu \mathrm{g} \mathrm{mL} \mathrm{m}^{-1}$ of curcumin solid dispersion were needed to keep $50 \%$ of the erythrocyte population intact for 60 and $120 \mathrm{~min}$, respectively. Curcumin provided a better protective capacity (lowest $\mathrm{IC}_{50}$ values), even better than trolox.

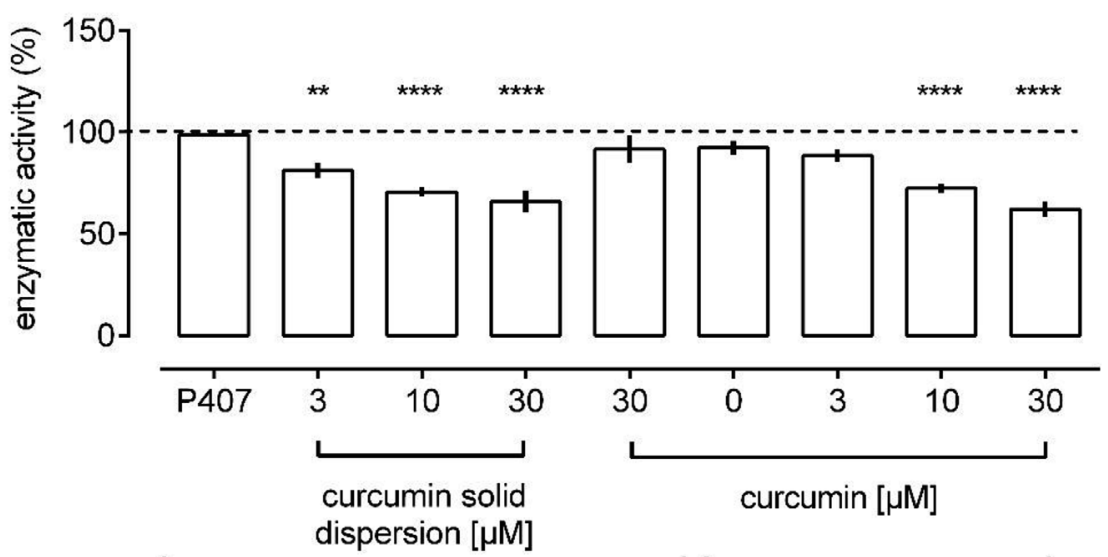

water
Fig. 5. In vitro effect of curcumin solid dispersion (concentration of $3-30 \mu \mathrm{M})$ and curcumin $(3-30 \mu \mathrm{M})$ on Glutathione S-Transferase (GST) activity in Drosophila melanogaster tissue. Values are mean \pm SEM $(n=4$ per group). Significance determined by one-way analyses of variance (ANOVA) followed by Tukey test. ${ }^{* *} \mathrm{p}<0.01$; $* * * * \mathrm{p}<0.0001$ in comparison to control (P407 = Poloxamer 407; DMSO $=$ dimethyl sulfoxide). 


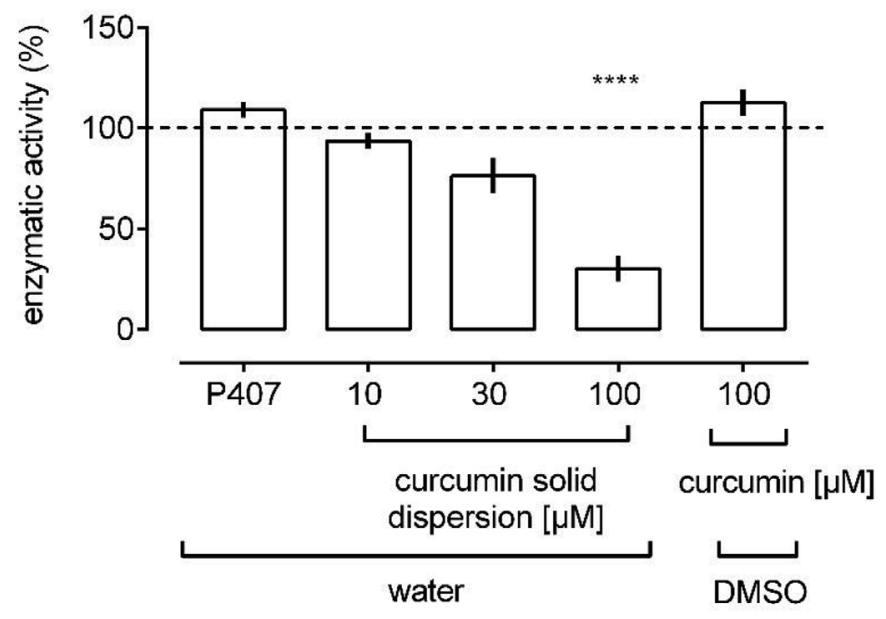

Fig. 6. Effects of curcumin nanoparticles (concentration of $10-100 \mu \mathrm{g} \mathrm{mL}^{-1}$ ) and curcumin $\left(100 \mu \mathrm{g} \mathrm{mL}^{-1}\right)$ on MAO-A enzyme activity in vitro rat brain homogenate. Values are mean \pm SEM ( $n=4$ per group). Significance determined by one-way analyses of variance (ANOVA) followed by Tukey test. $* * * * \mathrm{p}<0.0001$ in comparison to control (P407 = Poloxamer 407; DMSO $=$ dimethyl sulfoxide).

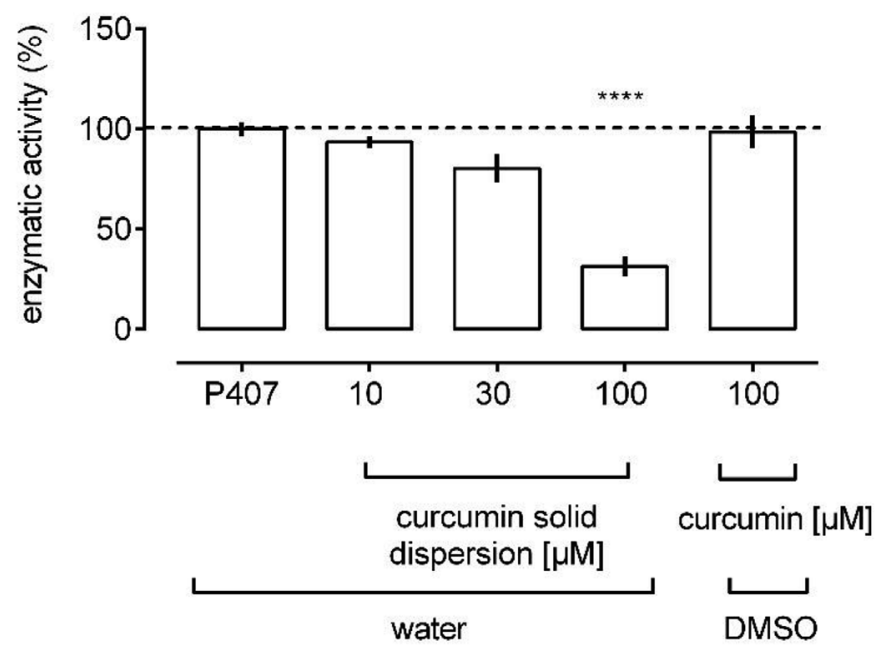

Fig. 7. Effects of curcumin nanoparticles (concentration of $10-100 \mu \mathrm{g} \mathrm{m}^{-1}$ ) and curcumin $\left(100 \mu \mathrm{g} \mathrm{mL}^{-1}\right)$ on MAO-B activity in vitro rat brain tissue. Values are mean \pm SEM ( $=4$ per group). Significance determined by one-way analyses of variance (ANOVA) followed by Tukey test. ${ }^{* * *} \mathrm{p}<0.0001$ in comparison to control (P407 = Poloxamer 407; DMSO = dimethyl sulfoxide).

Table 1

Antihemolytic (OxHLIA) and TBARS formation inhibition activities ( IC $_{50}$ values, $\left.\mu \mathrm{g} \cdot \mathrm{mL}^{-1}\right)^{\mathrm{a}}$ of the curcumin solid dispersion, curcumin and positive control (trolox).

\begin{tabular}{llll}
\hline & \multicolumn{2}{c}{ OxHLIA } & \multicolumn{2}{c}{ TBARS } \\
\cline { 2 - 3 } & $\Delta \mathrm{t}=60 \mathrm{~min}$ & $\Delta \mathrm{t}=120 \mathrm{~min}$ & \\
\hline Curcumin solid dispersion $^{\mathrm{b}}$ & $165 \pm 5$ & $297 \pm 9$ & $17 \pm 1$ \\
Curcumin $^{\mathrm{c}}$ & $7.9 \pm 0.2$ & $17.6 \pm 0.2$ & $1.04 \pm 0.06$ \\
Positive control (trolox) & $20.4 \pm 0.3$ & $44 \pm 1$ & $5.4 \pm 0.3$
\end{tabular}

a Statistical differences were found between curcumin solid dispersion and curcumin when using a two-tailed paired Student's t-test.

b Sample dispersed in PBS.

c Sample dispersed in PBS with 2.5\% DMSO.
However, 2.5\% DMSO was required to promote its dispersion in PBS (aqueous medium). In fact, it is worth noting that curcumin is highly hydrophobic and it tends to precipitate in water thus compromising the feasibility of the bioassays. On the other hand, curcumin solid dispersion is colloidally stable in water and was able to inhibit oxidative hemolysis. The antioxidant activity of curcumin has been described in the literature by conventional tests (Silva-Buzanello et al., 2016) and its activity was also demonstrated in the endogenous antioxidant system (Sankar et al., 2013). Deng et al. (2006) have demonstrated that curcumin analogues can inhibit the free radical-induced oxidative haemolysis of human erythrocytes, and that the phenolic groups in these molecules play a crucial role in their antioxidant/antihaemolytic activity.

The TBARS assay measures the compound's capacity to inhibit the formation of malondialdehyde and other reactive substances that are generated from the ex vivo decomposition of lipid peroxidation products. Porcine brain cells were used for this purpose, as they are biological substrates rich in polyunsaturated fatty acids. As shown in Table $1,17 \pm 1 \mu \mathrm{g} \mathrm{mL}^{-1}$ of curcumin solid dispersion were needed to provide $50 \%$ of antioxidant activity. In this assay, curcumin dispersed in $2.5 \%$ DMSO also had the lowest $\mathrm{IC}_{50}$ value $\left(1.04 \pm 0.06 \mu \mathrm{gL}^{-1}\right)$. In a previous study, Banerjee et al. (2008) demonstrated that curcumin is able to decrease the TBARS levels, as well as haemolysis, in human erythrocytes treated with this antioxidant. It was also shown that curcumin can decreases the formation of TBARS in plasma and rats liver (El-Demerdash et al., 2009).

\subsection{Anti-inflammatory and cytotoxic properties in cell lines}

The results of the performed cytotoxicity and anti-inflammatory activity assays using the curcumin solid dispersion are shown in Table 2.

Cytotoxic activity was found for all tumor cell lines, but no cytotoxicity was detected for the non-tumor PLP2 cells ( $\mathrm{GI}_{50}$ value $>400 \mu \mathrm{g} \mathrm{mL}^{-1}$ ). Cytotoxic effects of emulsified curcumin were already evaluated by Yoon et al. (2018) showing the increase in activity due to emulsification. This is in agreement with the results in Table 2, which means that the solid dispersion was also effective in improving the curcumin water affinity. In turn, no anti-inflammatory activity was detected against LPS-stimulated RAW 264.7 macrophages $\left(\mathrm{IC}_{50}\right.$ values $>400 \mu \mathrm{g} \mathrm{mL}^{-1}$ ).

It is known that curcumin has anti-proliferative and anti-inflammatory activities, but the poor water solubility limits its applications (Nair et al., 2012). However, the curcumin solid dispersion prepared in this study allowed to overcome the aqueous dispersibility limitation and thus revealing cytotoxic effects in aqueous medium. This result indicates the viability of administrating curcumin in vivo, avoiding the usage of toxic solvents such as DMSO, improving its clinical efficacy.

Table 2

Cytotoxicity ( $\mathrm{GI}_{50}$ values, $\mu \mathrm{g} \cdot \mathrm{mL}^{-1}$ ) and anti-inflammatory activity ( $\mathrm{IC}_{50}$ values, $\mu \mathrm{g} \cdot \mathrm{mL}^{-1}$ ) of the curcumin solid dispersion and positive control (ellipticine or dexamethasone).

\begin{tabular}{lll}
\hline & $\begin{array}{l}\text { Curcumin solid } \\
\text { dispersion }\end{array}$ & Positive control \\
\hline $\begin{array}{l}\text { Cytotoxic activity } \\
\text { NCI-H460 (non-small cell lung }\end{array}$ & $207 \pm 4$ & $\begin{array}{l}\text { Ellipticine } \\
\quad \text { carcinoma) }\end{array}$ \\
$\begin{array}{l}\text { HeLa (cervical carcinoma) } \\
\text { HepG2 (hepatocellular carcinoma) }\end{array}$ & $208 \pm 3 \pm 0.09$ \\
MCF-7 (breast carcinoma) & $240 \pm 7$ & $1.91 \pm 0.06$ \\
PLP2 (porcine liver primary cells) & $>400$ & $1.1 \pm 0.2$ \\
\hline Anti-inflammatory activity & & $1.1 \pm 0.2$ \\
RAW 264.7 (murine macrophages) & $>400$ & $3.2 \pm 0.7$ \\
\hline
\end{tabular}


Table 3

Mitotic indexes (MI) observed in meristematic tissues of Allium cepa roots exposed for 24 and $48 \mathrm{~h}$ to curcumin and curcumin solid dispersion.

\begin{tabular}{llll}
\hline \multirow{2}{*}{ Treatment } & \multicolumn{2}{l}{ Mitotic index (MI, \%) ${ }^{\mathrm{a}}$} \\
\cline { 2 - 4 } & $0 \mathrm{~h}$ & $24 \mathrm{~h}$ & \multicolumn{2}{l}{$48 \mathrm{~h}$} \\
\hline Curcumin solid dispersion & $58.4 \pm 0.31$ & $54.0 \pm 0.58$ & $52.7 \pm 1.30$ \\
Curcumin & $59.9 \pm 0.20$ & $57.0 \pm 0.24$ & $52.8 \pm 0.47$ \\
Paracetamol (positive control) & $52.0 \pm 0.48$ & $7.4^{\mathrm{a}} \pm 1.90$ & $1.0^{\mathrm{a}} \pm 1.30$ \\
\hline
\end{tabular}

a Values of mitotic index significantly differ from the mitotic index obtained from the other treatment groups.

Table 4

Types and number of cellular modifications observed in meristematic tissues of Allium cepa roots exposed for 24 and $48 \mathrm{~h}$.

\begin{tabular}{llllll}
\hline \multirow{2}{*}{$\begin{array}{l}\text { Exeatment } \\
\text { (h) }\end{array}$} & & \multicolumn{4}{l}{ Types of cellular changes } \\
\cline { 2 - 6 } & 0 & CM & ATB & MCN & AT \\
\hline curcumin solid dispersion & 0 & 00 & 00 & 00 & 00 \\
& 24 & 00 & 00 & 00 & 00 \\
& 48 & 00 & 00 & 01 & 01 \\
\cline { 2 - 6 } curcumin & 0 & 00 & 00 & 00 & 00 \\
& 24 & 00 & 00 & 00 & 00 \\
& 48 & 01 & 00 & 00 & 01 \\
\cline { 2 - 6 } Paracetamol (positive & 0 & 00 & 00 & 00 & 00 \\
control) & 24 & 48 & 87 & 74 & $209^{\mathrm{a}}$ \\
& 48 & 50 & 53 & 93 & $196^{\mathrm{a}}$ \\
\hline
\end{tabular}

CM: C-metaphase; ATB: anaphase and telophase bridge; MCN: micronucleous; AT: total cellular changes.

a Number of cell changes significantly differs from the number obtained for the other treatment groups.

\subsection{Cytotoxicity and genotoxicity test in root meristem cells of Allium cepa}

Mitotic indexes found in Allium cepa roots treated with curcumin and curcumin solid dispersion is presented in Table 3 and Table 4 shows the number of observed cellular modifications.

Curcumin and curcumin solid dispersion did not cause reduction of the cell division in the meristems of $A$. cepa roots when compared to the mitotic indexes obtained for the positive control. Also, treatments did not induce a significant number of cellular changes in the analyzed meristematic tissues (Table 4). Results indicated that curcumin and curcumin solid dispersion showed no cytotoxic and genotoxic potential under the evaluated experimental conditions.

\section{Conclusion}

Curcumin solid dispersion was obtained using Poloxamer 407 as the encapsulant agent. Physicochemical analyzes demonstrated that curcumin was entrapped inside the polymeric matrix and that colloidally stable nanoparticles were formed. The solid dispersion was able to inhibit the activity of the enzymes acetylcholinesterase (AChE) butyrylcholinesterase (BChE), glutathione S-transferase (GST), and monoamine oxidase (MAO A-B), protecting the erythrocyte membrane from oxidative damage, and preventing the formation of TBARS in aqueous medium. The curcumin solid dispersion showed cytotoxic effects on different tumor cell lines, but no cytotoxicity in non-tumor PLP2 cells. In addition, no genotoxicity was found in meristematic Allium cepa root cells. Results demonstrated that the constraints related with the low hydrophilicity of curcumin were overcome by using the solid dispersion technique, which contributed to the water affinity increase and the achievement of colloidal stability.

\section{Conflicts of interest}

Authors declare no conflicts of interest.

\section{Acknowledgements}

The authors are grateful to the Foundation for Science and Technology (FCT, Portugal) and FEDER under Programme PT2020 for financial support to CIMO (strategic project UID/AGR/00690/2013) and the research contracts of J. Pinela (Project AllNatt, POCI-01-0145FEDER-030463) and R. Calhelha. To the project POCI-01-0145-FEDER006984 - Associate Laboratory LSRE-LCM funded by FEDER through COMPETE2020 - Programa Operacional Competitividade e Internacionalização (POCI) - and by national funds through FCT. This work was also funded by the European Regional Development Fund through the Regional Operational Program North 2020, within the scope of Project NORTE-01-0145-FEDER-023289: DeCodE and Project Mobilizador Norte-01-0247-FEDER-024479: ValorNatural ${ }^{\circledR}$.

\section{Appendix A. Supplementary data}

Supplementary data to this article can be found online at https:// doi.org/10.1016/j.fct.2018.12.037.

\section{Transparency document}

Transparency document related to this article can be found online at https://doi.org/10.1016/j.fct.2018.12.037.

\section{References}

Abbasi, M.A., Ilyas, M., Aziz-Ur-Rehman, Sonia, A., Shahwar, D., Raza, M.A., Khan, K.M., Ashraf, M., Afzal, I., Ambreen, N., 2012. Curcumin and its derivatives: Moderate inhibitors of acetylcholinesterase, butyrylcholinesterase and trypsin. Sci. Iran 19, 1580-1583. https://doi.org/10.1016/j.scient.2012.10.014.

Abreu, R.M.V., Ferreira, I.C.F.R., Calhelha, R.C., Lima, R.T., Vasconcelos, M.H., Adega, F., Chaves, R., Queiroz, M.J.R.P., 2011. Anti-hepatocellular carcinoma activity using human HepG2 cells and hepatotoxicity of 6-substituted methyl 3-aminothieno[3,2-b] pyridine-2- carboxylate derivatives: In vitro evaluation, cell cycle analysis and QSAR studies. Eur. J. Med. Chem. 46, 5800-5806. https://doi.org/10.1016/j.ejmech.2011. 09.029 .

Agarwal, R., Goel, S.K., Behari, J.R., 2010. Detoxification and antioxidant effects of curcumin in rats experimentally exposed to mercury. J. Appl. Toxicol. 30, 457-468. https://doi.org/10.1002/jat.1517.

Araújo, C.R.M., Santos, V.L.A., Gonsalves, A.A., 2016. Acetilcolinesterase - AChE: uma enzima de interesse farmacológico. Rev. Virtual Quim. 8, 1818-1834. https://doi. org $/ 10.21577 / 1984-6835.20160122$

Banerjee, A., Kunwar, A., Mishra, B., Priyadarsini, K.I., 2008. Concentration dependent antioxidant/pro-oxidant activity of curcumin: Studies from AAPH induced hemolysis of RBCs. Chem. Biol. Interact. 174, 134-139. https://doi.org/10.1016/J.CBI.2008. 05.009.

Berg, J.M., Tymoczko, J.L., Stryer, L., 2014. Bioquímica, $7^{\text {a }}$. ed. .

Bianchi, P., Kunduzova, O., Masini, E., Cambon, C., Bani, D., Raimondi, L., Seguelas, M.H., Nistri, S., Colucci, W., Leducq, N., Parini, A., 2005. Oxidative stress by monoamine oxidase mediates receptor-independent cardiomyocyte apoptosis by serotonin and postischemic myocardial injury. Circulation 112, 3297-3305. https:// doi.org/10.1161/CIRCULATIONAHA.104.528133.

Bono, G.F., Simão-Silva, D.P., Batistela, M.S., Josviak, N.D., Dias, P.F.R., Nascimento, G.A., Souza, R.L.R., Piovezan, M.R., Souza, R.K.M., Furtado-Alle, L., 2015. Butyrylcholinesterase: $\mathrm{K}$ variant, plasma activity, molecular forms and rivastigmine treatment in Alzheimer's disease in a Southern Brazilian population. Neurochem. Int. 81, 57-62. https://doi.org/10.1016/j.neuint.2014.12.009.

Bradford, M.M., 1976. A rapid and sensitive method for the quantitation microgram quantities of protein utilizing the principle of protein-dye binding. Anal. Biochem. 72, 248-254.

Campos-Ventura, B., Angelis, D.F., Marin-Morales, M.A., 2016. Assessment of the cytotoxic, genotoxic and mutagenic effects of the commercial black dye in A. cepa cells before and after bacterial biodegradation treatment. Chemosphere 161, 325-332.

Carvalho, B.L., Sales, I.M.S., Peron, A.P., 2017. Cytotoxic, genotoxic and mutagenic potential of UHT whole milk. Food Sci. Technol 37 (2), 275-279.

Chandran, B., Goel, A., 2012. A Randomized, Pilot Study to Assess the Efficacy and Safety of Curcumin in Patients with Active Rheumatoid Arthritis. Phytother Res. 26, 1719-1725. https://doi.org/10.1002/ptr.4639.

de Almeida, M., da Rocha, B.A., Francisco, C.R.L., Miranda, C.G., Santos, P.D. de F., de Araújo, P.H.H., Sayer, C., Leimann, F.V., Gonçalves, O.H., Bersani-Amado, C.A., 2018. Evaluation of the in vivo acute antiinflammatory response of curcumin-loaded 
nanoparticles. Food Funct 9, 440-449. https://doi.org/10.1039/C7FO01616F.

de Oliveira, D.R., Schaffer, L.F., Busanello, A., Barbosa, C.P., Peroza, L.R., de Freitas, C.M., Krum, B.N., Bressan, G.N., Boligon, A.A., Athayde, M.L., de Menezes, I.R.A., Fachinetto, R., 2015. Silymarin has antioxidant potential and changes the activity of $\mathrm{Na}^{+} / \mathrm{K}^{+}$-ATPase and monoamine oxidase in vitro. Ind. Crop. Prod. 70, 347-355. https://doi.org/10.1016/j.indcrop.2015.03.060.

Deng, S.-L., Chen, W.-F., Zhou, B., Yang, L., Liu, Z.-L., 2006. Protective effects of curcumin and its analogues against free radical-induced oxidative haemolysis of human red blood cells. Food Chem. 98, 112-119.

El-Demerdash, F.M., Yousef, M.I., Radwan, F.M.E., 2009. Ameliorating effect of curcumin on sodium arsenite-induced oxidative damage and lipid peroxidation in different rat organs. Food Chem. Toxicol. 47, 249-254. https://doi.org/10.1016/J.FCT.2008.11. 013

Ellman, G.L., 1959. Tissue sulfhydryl groups. Arch. Biochem. Biophys. 82, 70-77. https:// doi.org/10.1016/0003-9861(59)90090-6.

Eloy, J.O., Marchetti, J.M., 2014. Solid dispersions containing ursolic acid in Poloxamer 407 and PEG 6000: A comparative study of fusion and solvent methods. Powder Technol. 253, 98-106. https://doi.org/10.1016/j.powtec.2013.11.017.

Evans, B.C., Nelson, C.E., Yu, S.S., Beavers, K.R., Kim, A.J., Li, H., Nelson, H.M., Giorgio, T.D., Duvall, C.L., 2013. Ex vivo red blood cell hemolysis assay for the evaluation of pH-responsive endosomolytic agents for cytosolic delivery of biomacromolecular drugs. JoVE, e50166.

Fiskesjö, G., 1993. The Allium test - a potential standard for the assessment of environmental toxicity. In: Gorsuch, J.W., Dwyer, F.J., Ingersoll, C.G., La Point, T.W. (Eds.), Environmental toxicology risk assessment. ASTM (American Society of Testing Materials) STP 1216, Philadelphia, pp. 331-345.

Gupta, S.C., Kim, J.H., Prasad, S., Aggarwal, B.B., 2010. Regulation of survival, proliferation, invasion, angiogenesis, and metastasis of tumor cells through modulation of inflammatory pathways by nutraceuticals. Cancer Metastasis Rev. 29, 405-434. https://doi.org/10.1007/s10555-010-9235-2.

Habig, W.H., Pabst, M.J., Jakoby, W.B., 1974. Glutathione S-Transferases: the first enzymatic step in mercapturic acid formation. J. Biol. Chem. 249, 7130-7139.

Hayeshi, R., Mutingwende, I., Mavengere, W., Masiyanise, V., Mukanganyama, S., 2007. The inhibition of human glutathione S-transferases activity by plant polyphenolic compounds ellagic acid and curcumin. Food Chem. Toxicol. 45, 286-295. https:// doi.org/10.1016/j.fct.2006.07.027.

Kaminaga, Y., Nagatsu, A., Akiyama, T., Sugimoto, N., Yamazaki, T., Maitani, T. Mizukami, H., 2003. Production of unnatural glucosides of curcumin with drastically enhanced water solubility by cell suspension cultures of Catharanthus roseus. FEBS Lett. 555, 311-316. https://doi.org/10.1016/S0014-5793(03)01265-1.

Khan, H., Marya Amin, S., Kamal, M.A., Patel, S., 2018. Flavonoids as acetylcholinesterase inhibitors: current therapeutic standing and future prospects. Biomed. Pharmacother. 101, 860-870. https://doi.org/10.1016/j.biopha.2018.03. 007.

Li, Q., Yang, H., Chen, Y., Sun, H., 2017. Recent progress in the identification of selective butyrylcholinesterase inhibitors for Alzheimer's disease. Eur. J. Med. Chem. 132, 294-309. https://doi.org/10.1016/j.ejmech.2017.03.062.

Lockridge, O., 2015. Review of human butyrylcholinesterase structure, function, genetic variants, history of use in the clinic, and potential therapeutic uses. Pharmacol. Ther. 148, 34-46. https://doi.org/10.1016/j.pharmthera.2014.11.011.

Morinan, A., Garratt, H.M., 1985. An improved fluorimetric assay for brain monoamine oxidase. J. Pharmacol. Methods 13, 213-223.

Moura, A.G., Santana, G.M., Ferreira, P.M.P., Sousa, J.M.C., Peron, A.P., 2016 Cytotoxicity of cheese and cheddar cheese food flavorings on A. cepa L. root meristems. Braz. J. Biol. 76 (2), 439-443.

Nair, K.L., Thulasidasan, A.K.T., Deepa, G., Anto, R.J., Kumar, G.S.V., 2012. Purely aqueous PLGA nanoparticulate formulations of curcumin exhibit enhanced antic ancer activity with dependence on the combination of the carrier. Int. J. Pharm. 425, 44-52. https://doi.org/10.1016/J.IJPHARM.2012.01.003.

Nass, R., Przedbordki, S., 2008. Parkinson's Disease, 1ed. Academic Press, New York.

Ou, X.-M., Chen, K., Shih, J.C., 2006. Monoamine oxidase A and repressor R1 are involved in apoptotic signaling pathway. Proc. Natl. Acad. Sci. U. S. A 103, 10923-10928. https://doi.org/10.1073/pnas.0601515103.

Pandey, U.B., Nichols, C.D., 2011. Human disease models in Drosophila melanogaster and the role of the fly in therapeutic drug discovery. Drug Deliv. 63, 411-436. https:// doi.org/10.1124/pr.110.003293.411.

Pandit, S., Kim, H.J., Kim, J.E., Jeon, J.G., 2011. Separation of an effective fraction from turmeric against Streptococcus mutans biofilms by the comparison of curcuminoid content and anti-acidogenic activity. Food Chem. 126, 1565-1570. https://doi.org/ 10.1016/j.foodchem.2010.12.005.

Paula, J.M., Pinto-Maglio, C.A.F., 2015. Technique to Obtain Mitotic Chromosomes of Conyza bonariensis L. Cronquist (Asteraceae). Am. J. Plant Sci. 6, 1466-1474. https://doi.org/10.4236/ajps.2015.69145.

Pinela, J., Barros, L., Carvalho, A.M., Ferreira, I.C.F.R., 2012. Nutritional composition and antioxidant activity of four tomato (Lycopersicon esculentum L.) farmer' varieties in Northeastern Portugal homegardens. Food Chem. Toxicol. 50, 829-834.

Pope, C.N., Brimijoin, S., 2018. Cholinesterases and the fine line between poison and remedy. Biochem. Pharmacol. 0-1. https://doi.org/10.1016/j.bcp.2018.01.044.

Prasad, S., Tyagi, A.K., Aggarwal, B.B., 2014. Recent developments in delivery, bioavailability, absorption and metabolism of curcumin: The golden pigment from golden spice. Cancer Res. Treat. 46, 2-18. https://doi.org/10.4143/crt.2014.46.1.2.

Prasad, S.N., Muralidhara, 2014. Neuroprotective effect of geraniol and curcumin in an acrylamide model of neurotoxicity in Drosophila melanogaster: Relevance to neuropathy. J. Insect Physiol. 60, 7-16. https://doi.org/10.1016/j.jinsphys.2013.10.003.

Prieto, M.A., Vázquez, J.A., 2014. A time-dose model to quantify the antioxidant responses of the oxidative hemolysis inhibition assay (OxHLIA) and its extension to evaluate other hemolytic effectors. BioMed Res. Int. 632971. 2014. https://doi.org/ $10.1155 / 2014 / 632971$

Rocha, B.A., Gonçalves, O.H., Leimann, F.V., Rebecca, E.S.W., Silva-Buzanello, R.A., Filho, L.C., Araújo, P.H.H., Cuman, R.K.N., Bersani-Amado, C.A., 2014. Curcumin encapsulated in poly-L-lactic acid improves its anti-inflammatory efficacy in vivo. Adv. Med. Plant Res. 2, 62-73.

Sankar, P., Telang, A.G., Kalaivanan, R., Karunakaran, V., Manikam, K., Sarkar, S.N., 2013. Effects of nanoparticle-encapsulated curcumin on arsenic-induced liver toxicity in rats. Environ. Toxicol. 628-637. https://doi.org/10.1002/tox.

Saranya, T.S., Rajan, V.K., Biswas, R., Jayakumar, R., Sathianarayanan, S., 2018. Synthesis, characterisation and biomedical applications of curcumin conjugated chitosan microspheres. Int. J. Biol. Macromol. 110, 227-233. https://doi.org/10. 1016/j.ijbiomac.2017.12.044.

Silva-Buzanello, R.A. da, Souza, M.F. de, Oliveira, D.A. de, Bona, E., Leimann, F.V., Cardozo Filho, L., Araújo, P.H.H. de, Ferreira, S.R.S., Gonçalves, O.H., 2016. Preparation of curcumin-loaded nanoparticles and determination of the antioxidant potential of curcumin after encapsulation. Polímeros 26, 207-214. https://doi.org/ 10.1590/0104-1428.2246.

Sobral, F., Sampaio, A., Falcão, S., Queiroz, M.J.R.P., Calhelha, R.C., Vilas-Boas, M., Ferreira, I.C.F.R., 2016. Chemical characterization, antioxidant, anti-inflammatory and cytotoxic properties of bee venom collected in Northeast Portugal. Food Chem. Toxicol. https://doi.org/10.1016/j.fct.2016.06.008.

Soto-Otero, R., Méndez-Alvarez, E., Hermida-Ameijeiras, a, Sánchez-Sellero, I., CruzLandeira, a, Lamas, M.L., 2001. Inhibition of brain monoamine oxidase activity by the generation of hydroxyl radicals: potential implications in relation to oxidative stress. Life Sci. 69, 879-889.

Souza, A.H.P., Corrêa, R.C.G., Barros, L., Calhelha, R.C., Santos-Buelga, C., Peralta, R.M., Bracht, A., Matsushita, M., Ferreira, I.C.F.R., 2015. Phytochemicals and bioactive properties of Ilex paraguariensis: An in-vitro comparative study between the whole plant, leaves and stems. Food Res. Int. 78, 286-294. https://doi.org/10.1016/j. foodres.2015.09.032.

Takebayashi, J., Iwahashi, N., Ishimi, Y., Tai, A., 2012. Development of a simple 96-wel plate method for evaluation of antioxidant activity based on the oxidative haemolysis inhibition assay (OxHLIA). Food Chem. 134, 606-610.

Vasconcelos, T., Sarmento, B., Costa, P., 2007. Solid dispersions as strategy to improve oral bioavailability of poor water soluble drugs. Drug Discov. Today 12, 1068-1075. https://doi.org/10.1016/j.drudis.2007.09.005.

Villarinho, J.G., Fachinetto, R., Pinheiro, F. de V., Sant'Anna, G. da S., Machado, P., Dombrowski, P.A., Cunha, C. da, Cabrini, D. de A., Martins, M.A.ô.P., Bonacorso, H.G., Zanatta, N., Rubin, M.A., Ferreira, J., 2012. Antidepressant-like effect of the novel MAO inhibitor 2-(3,4-dimethoxy-phenyl)-4,5-dihydro-1H-imidazole (2-DMPI) in mice. Prog. Neuro Psychopharmacol. Biol. Psychiatr. 39, 31-39. https://doi.org/ 10.1016/j.pnpbp.2012.04.007.

Yoon, H.J., Zhang, X., Kang, M.G., Kim, G.J., Shin, S.Y., Baek, S.H., Lee, B.N., Hong, S.J., Kim, J.T., Hong, K., Bae, H., 2018. Cytotoxicity evaluation of turmeric extract incorporated oil-in-water nanoemulsion. Int. J. Mol. Sci. 19, 1-12. https://doi.org/10. 3390/ijms19010280.

Youdim, M.B.H., Bakhle, Y.S., 2006. Monoamine oxidase: Isoforms and inhibitors in Parkinson's disease and depressive illness. Br. J. Pharmacol. 147. https://doi.org/10. 1038/sj.bjp.0706464. 